Article

\title{
How Accurate Can UWB and Dead Reckoning Positioning Systems Be? Comparison to SLAM Using the RPLidar System
}

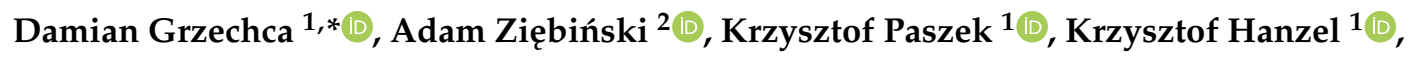 \\ Adam Giel ${ }^{1}$, Marcin Czerny ${ }^{1}$ and Andreas Becker ${ }^{3}$ \\ 1 Department of Electronics, Electrical Engineering and Microelectronics, Silesian University of Technology, \\ Akademicka 16, 44-100 Gliwice, Poland; Krzysztof.Paszek@polsl.pl (K.P.); Krzysztof.Hanzel@polsl.pl (K.H.); \\ gielupl@gmail.com (A.G.); czernymarcin@gmail.com (M.C.) \\ 2 Department of Distributed Systems and Informatic Devices, Silesian University of Technology, \\ Akademicka 16, 44-100 Gliwice, Poland; Adam.Ziebinski@polsl.pl \\ 3 Faculty of Information Technology, University of Applied Science and Arts, Sonnenstr. 96, \\ 44139 Dortmund, Germany; Andreas.Becker@fh-dortmund.de \\ * Correspondence: damian.grzechca@polsl.pl
}

Received: 29 May 2020; Accepted: 1 July 2020; Published: 5 July 2020

\begin{abstract}
This paper compares two positioning systems, namely ultra-wideband (UWB) based micro-location technology and dead reckoning and a RPLidar based simultaneous localization and mapping (SLAM) solution. This new approach can be used to improve the quality of the positioning system and increase the functionality of advanced driver assistance systems (ADAS). This is achieved by using stationary nodes and UWB tags on the vehicles. Thus, the redundancy of localization can be achieved by this approach, e.g., as a backup to onboard sensors like RPlidar or radar. Additionally, UWB based micro-location allows additional data channels to be used for communication purposes. Furthermore, it is shown that the regular use of correction data increases UWB and dead reckoning accuracy. These correction data can be based on onboard sensors. This shows that it is promising to develop a system that fuses onboard sensors and micro-localization for safety-critical tasks like the platooning of commercial vehicles.
\end{abstract}

Keywords: dead reckoning; UWB; positioning system; RPLidar; SLAM

\section{Introduction}

The current massive car traffic requires changes in methods of transport utilization. One of the ways to increase the efficiency of transport utilization is the usage of an automatic highway system (AHS) [1], including automated platooning [2]. To be able to use this technology, it is necessary to be able to determine the distance to the preceding vehicle [3] and to predict the path it moves on. Modern cars use, e.g., lidar technology to ensure this purpose. Thanks to the reflection of the laser beam, it is able to provide the distance to the object. However, this solution has its drawbacks, not only related to the reflection itself (associated, for example, with the surface or the need to mount at a certain height), but also with the possibility of distortions, especially in the form of weather conditions.

However, there should be a way to ensure maximum security and, at the same time, take advantage of such things as increasing traffic safety on roads and allow to reduce fuel consumption [4]. Positioning methods should also, in the future, enable the implementation of autonomous driving [5], which is associated with many challenges not only from the point of view of algorithmics, but also the accuracy of acquired position data. Often, in such systems, various types of measurements on the basis of radar and laser sensors and advanced solutions like ADAS modules [6] which allow to monitor the 
environment are used. Many positioning systems should be considered in the positioning process. All their advantages (e.g., high accuracy, high data rate) should be used to eliminate all disadvantages (low accuracy, low data rate, costs, precision) of an individual system [7]. Some of them used UWB [8] and inertial measurement unit (IMU), e.g., for range-based cooperative localization method [9].

The movement of vehicles close to each other with high speed influences the appearance of additional dangerous factors. Therefore, the use of a data fusion algorithm $[10,11]$ that will take into account the measurement of speed [12] and distance to the preceding car and other significant factors such as recognized road signs [13,14], road infrastructure [15], and driver [16] or system behavior is essential [17]. Additionally, the time to retrieve information from the environment by sensors and fast processing of those data is important. As the speed increases, it becomes crucial to receive information as soon as possible. The current verification of the measurement and control modules to ensure their correct operation is also important.

Information about, e.g., traffic, regulations, and speed limits, can be obtained from the UWB infrastructure, which allows to send additional data in a datagram. Communication between vehicles $[18,19]$ is also possible, but it has to be secure. In particular, information about the vehicle's current and expected maneuvers and the speed of the vehicle can be useful to avoid collisions. Communication with infrastructure and other road users, e.g., cyclists and pedestrians [20], can reduce the number of violent and dangerous maneuvers and situations. So, the integration of several technologies [21] is necessary for safe movement [22,23] on public roads.

The main goal of this research is to obtain the most accurate position by the use of data fusion using the UWB system, IMU, and RPLidar. In this article, low-cost solutions based on an encoder, i.e., three-dimensional attitude heading reference system (myAHRS+)(dead reckoning), 360-degree 2D laser scanner (RPLidar), and positioning based on UWB system (Pozyx), are presented. The following sections first introduce the architecture of the remote-controlled platform, parameters, as well as pros and cons of each used positioning systems. Next, the trilateration method and research environment are described. Finally, the conducted research with results and discussion are presented. Such a solution could be used to improve the quality of the positioning system and increase the functionality of ADAS modules.

\section{The Architecture of the Remote-Controlled Platform}

One of the ways to test positioning systems in real-world scenarios is to use them on mobile platforms, that allow collecting data from sensors and steering indoors. Because of that, a popular radio-controlled (RC) platform model was equipped with, among others, single-board computers, microcontrollers, sensors, communication devices, and a power supply. The final platform for the research purpose is presented in Figure 1.
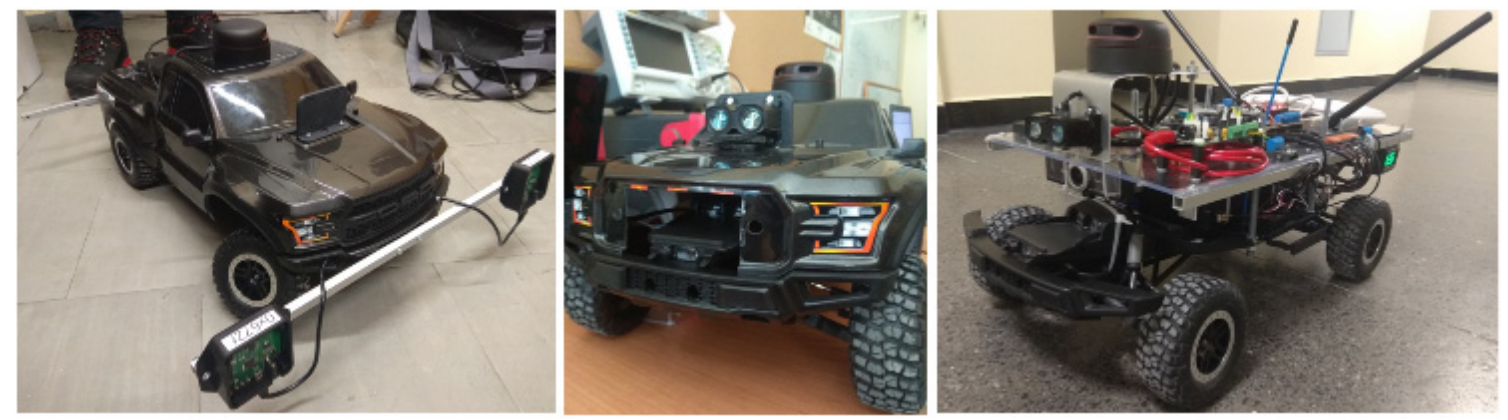

Figure 1. The evolution of the mobile platform used in tests.

The diagram of connections between used components is presented in Figure 2. Due to hardware limitations and data transfer components like camera, RPLidar and IMU have been separated from the UWB modules (POZYX on the schematic diagram) and encoders. A Raspberry Pi computer was 
used to remote control of the vehicle, control the motor and steering servo by pulse width modulation (PWM signal). Additionally, it collects sensors data, particularly from an encoder (possible because of intermediary Arduino) and Pozyx (based on the Dwcawave DW1000) [24]. The Odroid computer was used to collect data from other sensors, like Lidars (Garmin LiteV3 HP, Lidar Continental, RPlidar), video camera, and IMU myAHRS+. These two computers were connected to each other by Ethernet cables to a Wi-Fi router that could also be used to make a wireless connection with a personal computer to monitor the system work.

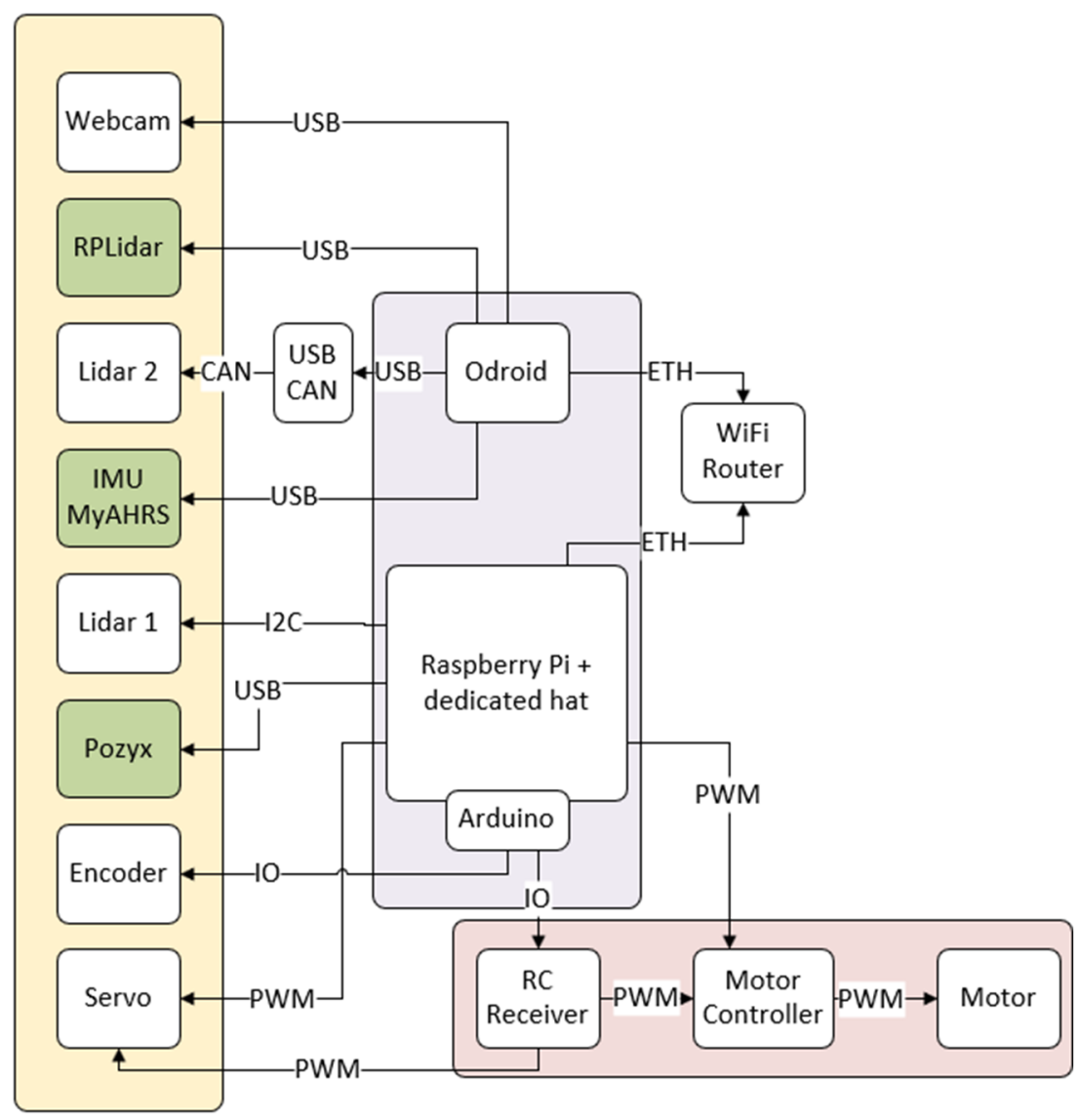

Figure 2. The diagram of connections between used components.

One can notice that the platform has devices on two levels. The upper level shown in Figure 3 are as follows: (1) Wi-Fi router, for connecting with operator computer, (2) voltmeter, for battery condition observation, (3) $9 \mathrm{~V}$ voltage regulator, for supplying Wi-Fi router, (4) battery pack, for supplying the steering servo and motor on the platform, (5) power switch, (6) Raspberry Pi with a dedicated hat, for collecting data from sensors and controlling the platform, (7) 5 A fuse, (10) RPLidar, rotating Lidar dedicated to scanning the area, (11) USB/UART converter, for communication between Odroid XU 4 and Raspberry Pi, (13) stepdown voltage converter, for supplying sensors and computers on the platform, (14) USB hub-expanding the available USB ports, (15) Odroid XU4, for collecting data from RPLidar and controlling the platform, (16) connector, (17) external power supply, an alternative to the battery pack when the platform is not in motion, and (18) a UWB anchor, for positioning of the platform (Pozyx system). 


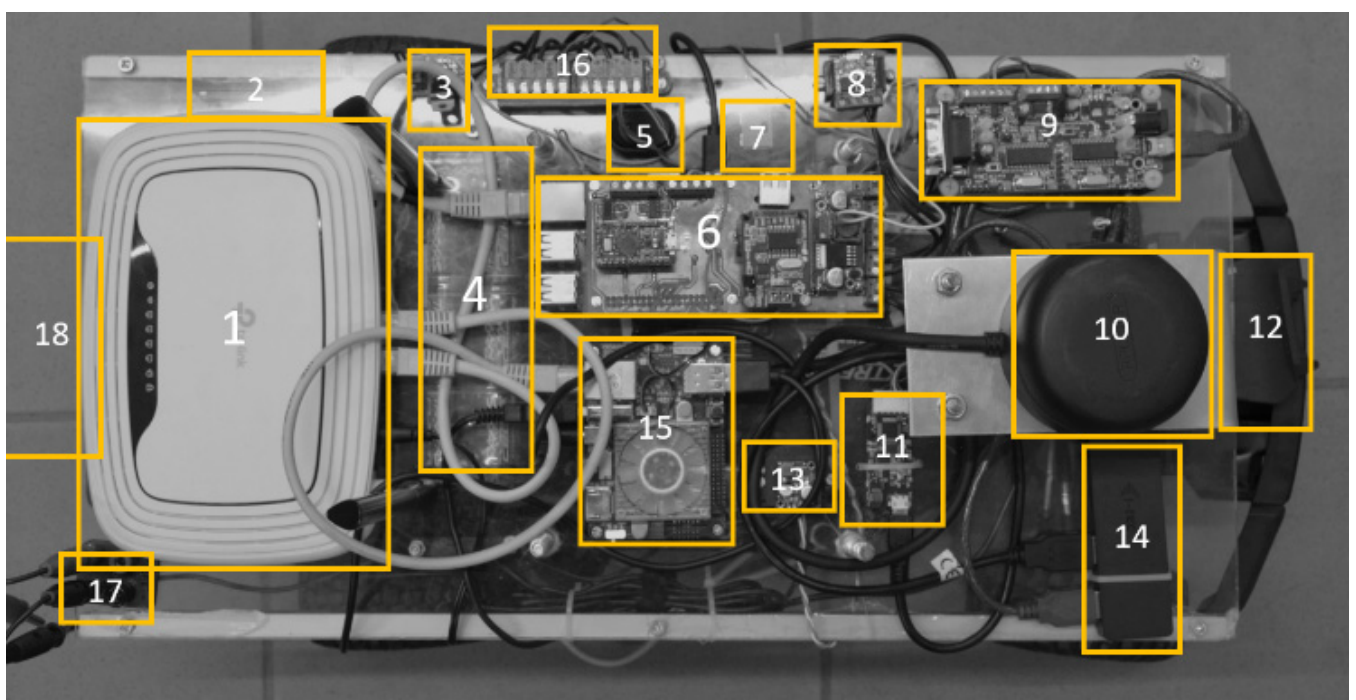

Figure 3. The arrangement of individual modules on the surface of the mobile platform.

The lower-level components are shown in Figure 4: (1) motor, (2) encoder, to measure the speed of the platform, (3) motor controller, (4) $12 \mathrm{~V}$ battery, for powering the motor, (5) connector, (6) servo, (7) IMU myAHRS+, for collecting data about acceleration and orientation, (8) RC receiver, for manual remote control, and (12) a USB webcam.

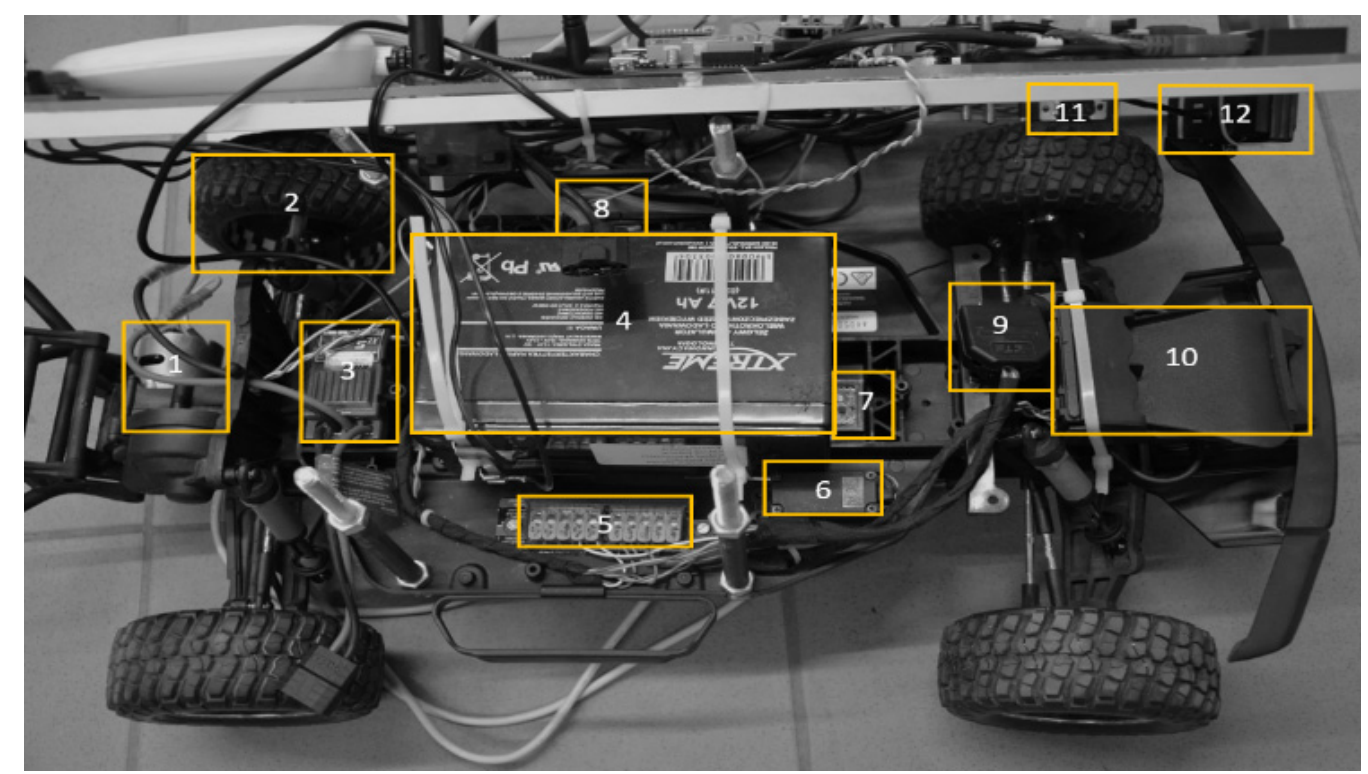

Figure 4. The arrangement of individual modules below the top board of the mobile platform.

The chosen parameters of positioning subsystems or devices used in the RC platform and related systems are listed in the Table 1 Advantages, disadvantages and parameters related to devices used in the RC platform and related systems. 
Table 1. Advantages, disadvantages and parameters related to devices used in the RC platform and related systems.

\begin{tabular}{|c|c|c|c|}
\hline & UWB & IMU & RPLidar \\
\hline Positioning algorithm & Trilateration & Dead reckoning & SLAM \\
\hline sampling rate & $19 \mathrm{~Hz}$ & $56 \mathrm{~Hz}$ & $13 \mathrm{~Hz}$ \\
\hline $\begin{array}{l}\text { Device limitations e.g., } \\
\text { coverage and other } \\
\text { parameters }\end{array}$ & $\begin{array}{l}\text { Up to } 40 \mathrm{~m} \times 40 \mathrm{~m} \text {, } \\
\text { Max } 5 \text { tracked devices } \\
\text { appx. } 50 \text { readings per sec for } \\
2 \text { device setup }\end{array}$ & $\begin{array}{l}\text { Coverage not applicable, } \\
\text { Triple axis 16-bit } \\
\text { gyroscope } \\
\text { Triple axis 16-bit accelerometer } \\
\text { accuracy } \\
\pm 0.2^{\circ} \text {. } \\
\text { Triple axis 13-bit } \\
\text { magnetometer }\end{array}$ & $\begin{array}{l}\text { Coverage not applicable } \\
\text { (depends on surrounding } \\
\text { environment), Measuring } \\
\text { range: } 0.15-12 \mathrm{~m} \text { Accuracy: } \\
<1 \% \text { of distance } \\
\text { Distance resolution: } 1 \mathrm{~mm} \\
\text { Angular resolution: } 0.9^{\circ} \\
\text { Time of single } \\
\text { measurement: } 0.25 \mathrm{~ms}\end{array}$ \\
\hline Advantages & $\begin{array}{l}\text { - High accuracy } \\
\text { - Not dependent on the } \\
\text { surface or experiment setup. } \\
\text { Coverage } 100 \%\end{array}$ & $\begin{array}{l}\text { - High data rate } \\
\text { - Not dependent on } \\
\text { environment setup } \\
\text { - Can be used in open areas } \\
\text { Coverage } 100 \%\end{array}$ & $\begin{array}{l}\text { - All positions are } \\
\text { determined independently } \\
\text { - Moderately high data } \\
\text { acquisition frequency } \\
\text { Possible V2V data } \\
\text { transmission }\end{array}$ \\
\hline Disadvantages & $\begin{array}{l}\text { - The surroundings should } \\
\text { not be changed rapidly } \\
\text { There must be enough } \\
\text { characteristic points around } \\
\text { to achieve localization }\end{array}$ & $\begin{array}{l}\text { - Accumulate error } \\
\text { over time } \\
\text { - Tire slip errors } \\
\text { - Reference point is required }\end{array}$ & $\begin{array}{l}\text { - Requires setup which is } \\
\text { not possible everywhere } \\
\text { - Need infrastructure } \\
\text { Coverage depending on } \\
\text { infrastructure }\end{array}$ \\
\hline
\end{tabular}

\section{The UWB Positioning System}

UWB is one of the most promising technologies for position determination and allows object tracking. This technology is still very actively researched and developed. UWB is a radio communication technique involving the transmission of very short radio pulses, which allows for the transmission of large amounts of data (up to $1.6 \mathrm{~Gb} / \mathrm{s}$ ) over a short distance (up to $10 \mathrm{~m}$ ).

The basic feature that distinguishes this technology from conventional radio communication is the fact that conventional systems use signal amplitude, phase, or frequency modulation. The UWB sends information generating impulses of constant amplitude, with a time regime. Further, it uses a wideband for implementing time modulation. The system offers distance measurements based on the time of flight ( $\mathrm{ToF}$ ) method. It enables compensation of the multipath propagation and allows the use of UWB as positioning technology.

The distance between the transmitter and receiver (tag and anchor) could be determined by measuring the time. The principle of determining the relative position between anchor and tag is presented in Figure 5. Given the exact time of sending the frame, the exact time of receiving the frame, and the speed of the signal (speed of light), the distance between the transmitter and receiver can be determined. Then, the trilateration algorithm $[25,26]$ is used. Three reference points allow to calculate the position of the object in a two-dimensional plane. The transmitter sends a frame containing the moment of sending, while the receiver receives the frame and sends it back to the tag, which calculates the distance between the receiver and the transmitter using the ToF and speed of the wave propagation (speed of light). 


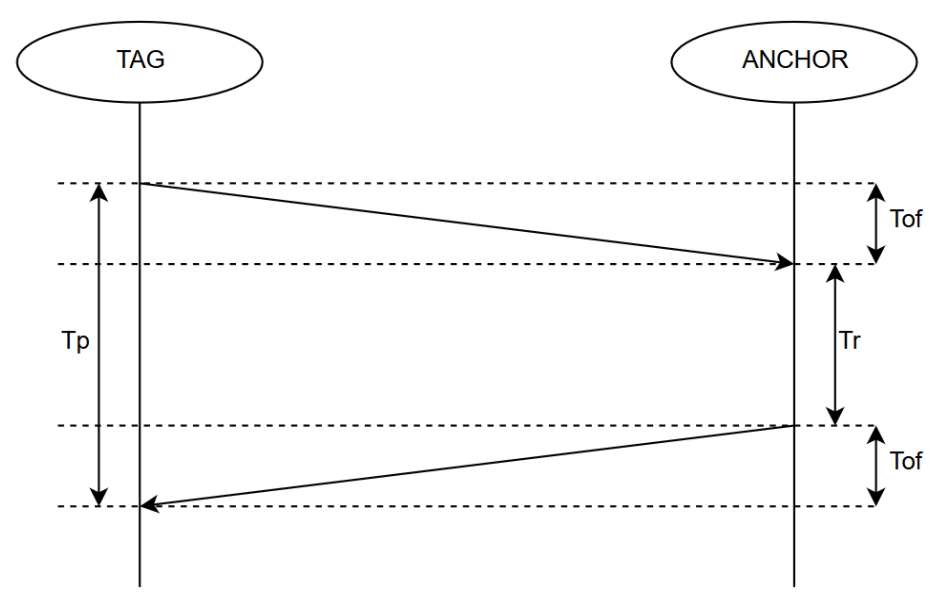

Figure 5. The principle of determining the relative position between anchor and tag.

According to Fang's method [27], one sphere center is placed at the origin of the elevated plane, the second along with the x-axis, and the third orthogonally to the previous two, as presented in Figure 6.

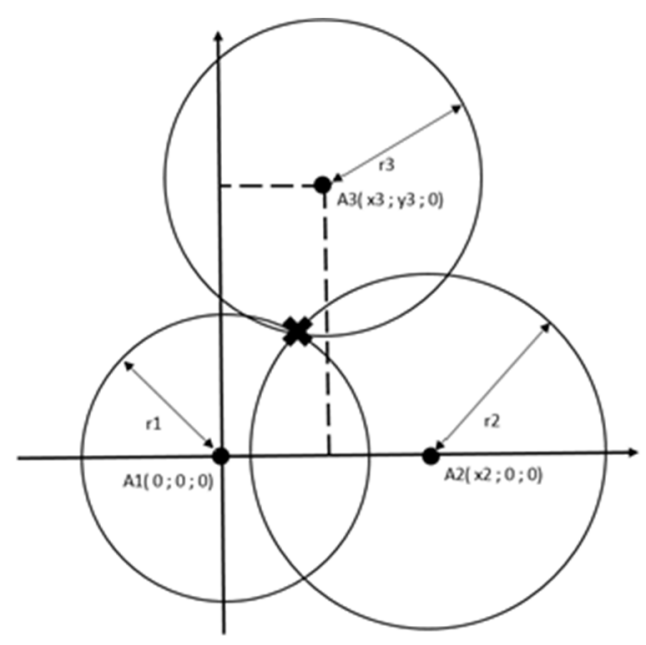

Figure 6. An example of trilateration.

Equations below depict anchor coordinates. Starting from points A1, A2, and A3 given by (1),

$$
A 1(0 ; 0 ; 0) A 2\left(x_{2} ; 0 ; 0\right) A 3\left(x_{3} ; y_{3} ; 0\right)
$$

and the radius of the circles (2)

$$
\begin{gathered}
r_{1}^{2}=x^{2}+y^{2}+z^{2} \\
r_{2}^{2}=\left(x-x_{2}\right)^{2}+y^{2}+z^{2} \\
r_{3}^{2}=\left(x-x_{3}\right)^{2}+\left(y-y_{3}\right)^{2}+z^{2}
\end{gathered}
$$

$x, y$, and, $z$ can be determined:

$$
\begin{gathered}
x_{p}=\frac{r_{1}^{2}-r_{2}^{2}+x_{2}^{2}}{2 x_{2}} \\
y_{p}=\frac{r_{1}^{2}-r_{3}^{2}+x_{3}^{2}+y_{3}^{2}-\left(2 x_{3} x_{p}\right)}{2 y_{3}} \\
z=\sqrt{r_{1}^{2}-x_{p}^{2}-y_{p}^{2}}
\end{gathered}
$$




\section{Dead Reckoning}

Dead reckoning is based on another approach [28].The current position of the object $\left(x_{t}, y_{t}\right)$ is determined based on the known position in the past $\left(x_{t-1}, y_{t-1}\right)$, the direction (given by yaw angle $\alpha$ ) and speed $(v)$ with which it moves [29]. IMUs with encoders (odometry) usually acquire it. This technique requires knowledge of the initial position $(x(0), y(0))$, which should be as accurate as possible. The speed of the platform is calculated based on encoder readings (4). The wheel rotation was measured with an accuracy of $10 \mathrm{deg}$. Then, in the subsequent moments of time, the travelled distance (s) (5) and direction of the movement $(\alpha)$ are used for new position calculation (6). Each subsequent update position is burdened with an error that is accumulated (by the data source to the calculated speed and direction of movement of the subject).

$$
v(t)=2 \pi r \cdot \theta \cdot t
$$

where $r$ refers to platform wheels radius, $\theta$, the wheel rotation angle, and $t$ the time elapsed since the previous measurements reading.

$$
\begin{gathered}
s=\int_{t-1}^{t} v(t) d t \\
\left\{\begin{array}{c}
x_{t}=x_{t-1}+s \cos (\alpha) \\
y_{t}=y_{t-1}+s \sin (\alpha)
\end{array}\right.
\end{gathered}
$$

An additional positioning method should be used to improve the accuracy and reduce the accumulated error of the position obtained by dead reckoning. This can be achieved by systematically updating the current position (initial position for dead reckoning) by the system with higher accuracy (see Figure 7). The data rate of that positioning system can be lower than that of the IMU/myAHRS+.

A new accurate position obtained from Lidar (or another high accurate positioning system) can be used as a new initial point for the dead reckoning (or another system with high data rate but lower accuracy), so the accumulated error is removed.

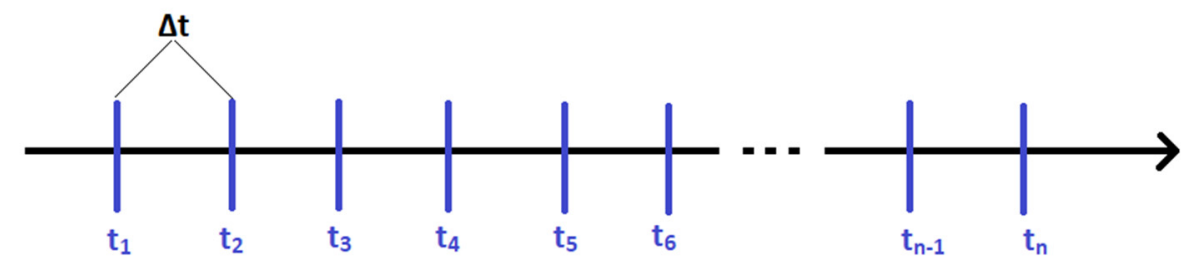

Figure 7. The sample route of the vehicle along with corrections of position from the UWB system or dead reckoning based on the readings (corrections) from the Lidar every $\Delta t=\{1 \mathrm{~s}$ or $3 \mathrm{~s}\}$.

\section{The Research Environment}

The second more accurate system is needed to evaluate the system under test. RPLidar and information from encoders are used as a reference system (system with greater accuracy) to validate the UWB positioning system and dead reckoning. The main advantages of RPLidar are high accuracy, resolution, and relatively fast acquisition time. The stationary and characteristic reference points can be used to determine the accurate position of the mobile platform in a local coordinate system. These points can be detected by scanning the area surrounding the mobile platform by making use of a rotating lidar scanner (RPLidar). If these points are fixed, then by measuring differences in the historic relative position of these points to the moving mobile platform, the change of the vehicle orientation and position can be determined.

The UWB positioning system is the main core of this research. The applied UWB system consists of a set of anchors (reference points) and tags. The purpose of this system is to determine the position of the tags with respect to known anchors positions. All components are based on the UWB system, incorporating Decawave DWM1000 and STM microcontrollers. Functions the anchor or tag can be 
assigned to devices as desired. Differences between components do not affect their basic functionality determining position and distance.

A robotic operating system (ROS) was used for logging and processing data. It is a simple way to create robotics applications with many off-the-shelf nodes with good documentation. ROS applications allow logging data from multiple sources and timestamp them. The Hector SLAM package was used to create a reference path based on RPLidar.

The graph ROS odometry topic structure is presented in Figure 8. The Node/Dead_reckoning subscribes/Wheel_Speed topic with wheel speed data and /Imu_Data topic with yaw rate data. The output was published by Odom topic and contains position $\mathrm{x}$ and $\mathrm{y}$ in meters.

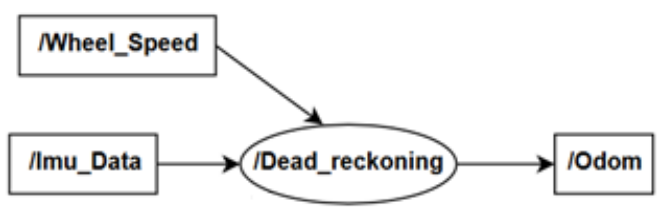

Figure 8. The ROS odometry topics structure.

The ROS RviZ tool was used to visualize the state of the mobile platform in a three-dimensional environment. It allows displaying 3D models, point clouds, markers, creating maps, paths, trajectories, etc. All this is based on the mechanisms of publishing and subscribing to relevant types of messages. It gives a spectacular visual effect and allows for the initial verification of the measurements and their reference to reality. Figure 9 presents a visualization of the lidar scan points cloud and the generated map of the examined corridor. In the bottom left corner, the view from a camera connected to the mobile platform is presented, so it is easier to recognize the observed environment.
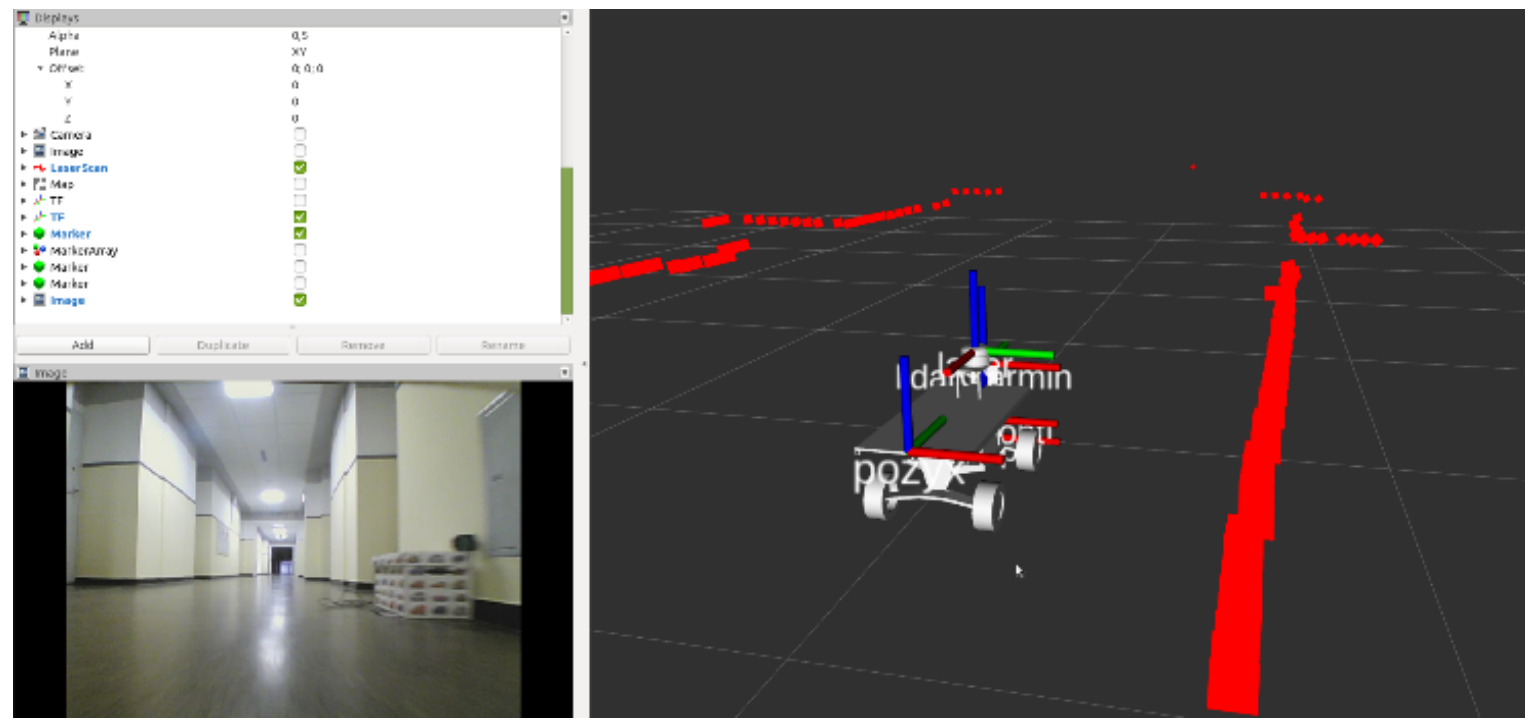

Figure 9. The visualization of the lidar scan points cloud and the generated map of the examined corridor using RviZ tool.

Lidar was used to create the map and determine the position, i.e., the SLAM technique. For the tests, Hector SLAM, one of the most popular SLAM implementations, was used. Hector SLAM was created at the University of Darmstadt [30]. The output is a map and the position of the object. The positions determined using this method will be the references for the other positioning methods. Mapping and location errors are cumulative. Incorrect estimation of the position translates into incorrect positioning of objects on the map. However, incorrect determination of the position of objects makes it difficult to determine its own position changes. The accumulation of errors can contribute to incorrect creation of a map in the mobile platform's memory, not related to reality. 
The positioning algorithms (presented in Figure 10) is based on taking measurements from Lidar, IMU, encoder and UWB system. In a given time interval the correction vector is calculated based on the current reference position from lidar and position indicated by UWB/dead reckoning values. The localization is determined with current measurements from UWB/dead reckoning and the last calculated correction vector.

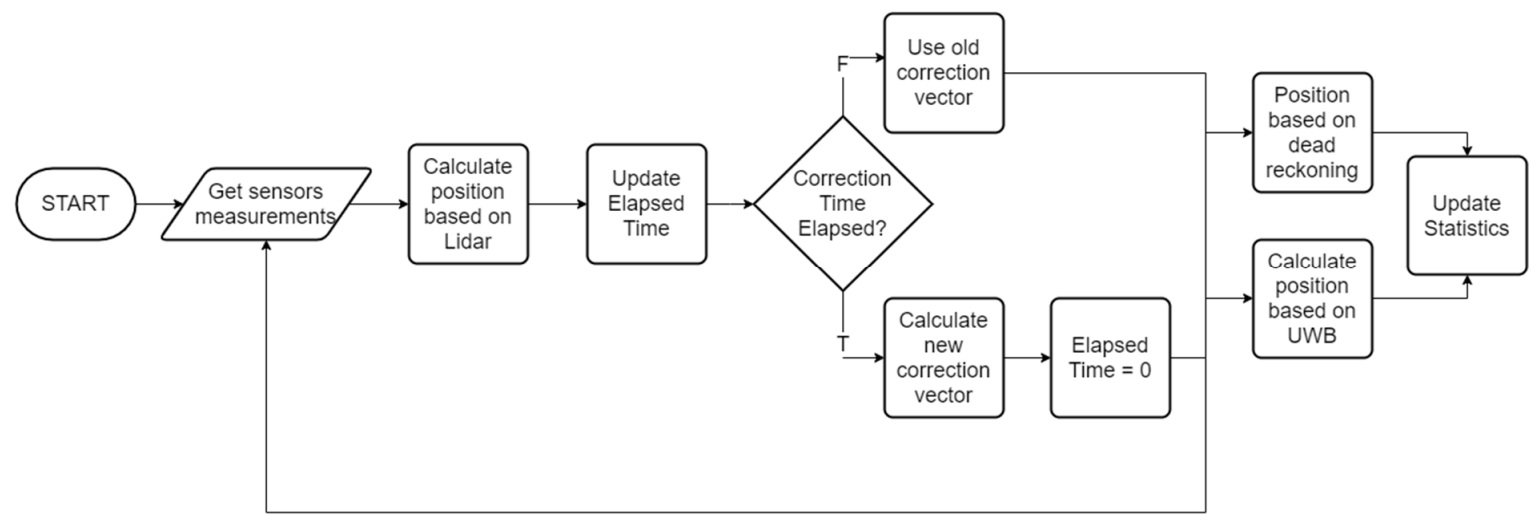

Figure 10. Block diagram of data flow in the prepared algorithm.

Data from Lidar were used as a reference for other positioning methods. All information about position obtained from the UWB system or dead reckoning was compared to the reference path determined by Lidar and Hector SLAM. The example of a comparison of two approaches (SLAM and dead reckoning) is presented in Figure 11. All the sensors were mounted on a built RC model. The distances between the sensors' mounting points are taken into account when calculating the position of the object. Data from tests were logged using a rosbag file, which contains data with timestamps.

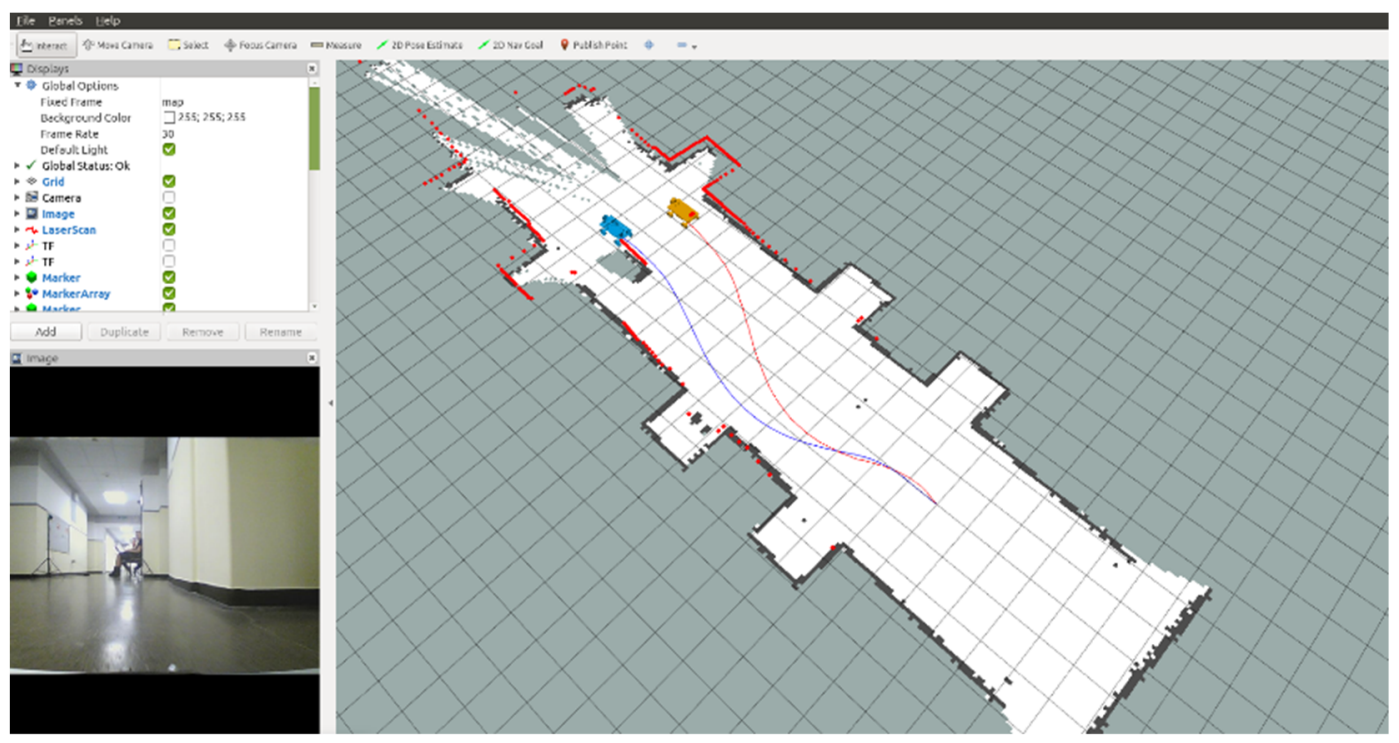

Figure 11. The comparison of SLAM (blue path) and dead reckoning (red path).

The goal of the research was to compare two methods of object positioning:

- Dead reckoning based on the data from myAHRS+ (angular acceleration) and from the encoder mounted on the rear wheel (speed of the vehicle),

- UWB (position in local reference system) with SLAM based on RPLidar data (for environment scanning). 
The tests were conducted in three measurement environments (Figure 12). Two of them were arranged in the corridor (part A-long narrow corridor, part B-section in front of elevators, space disturbed by the presence of a staircase). The third was located in the laboratory room (part C—space with many small objects, e.g., chairs, tables, laboratory equipment).

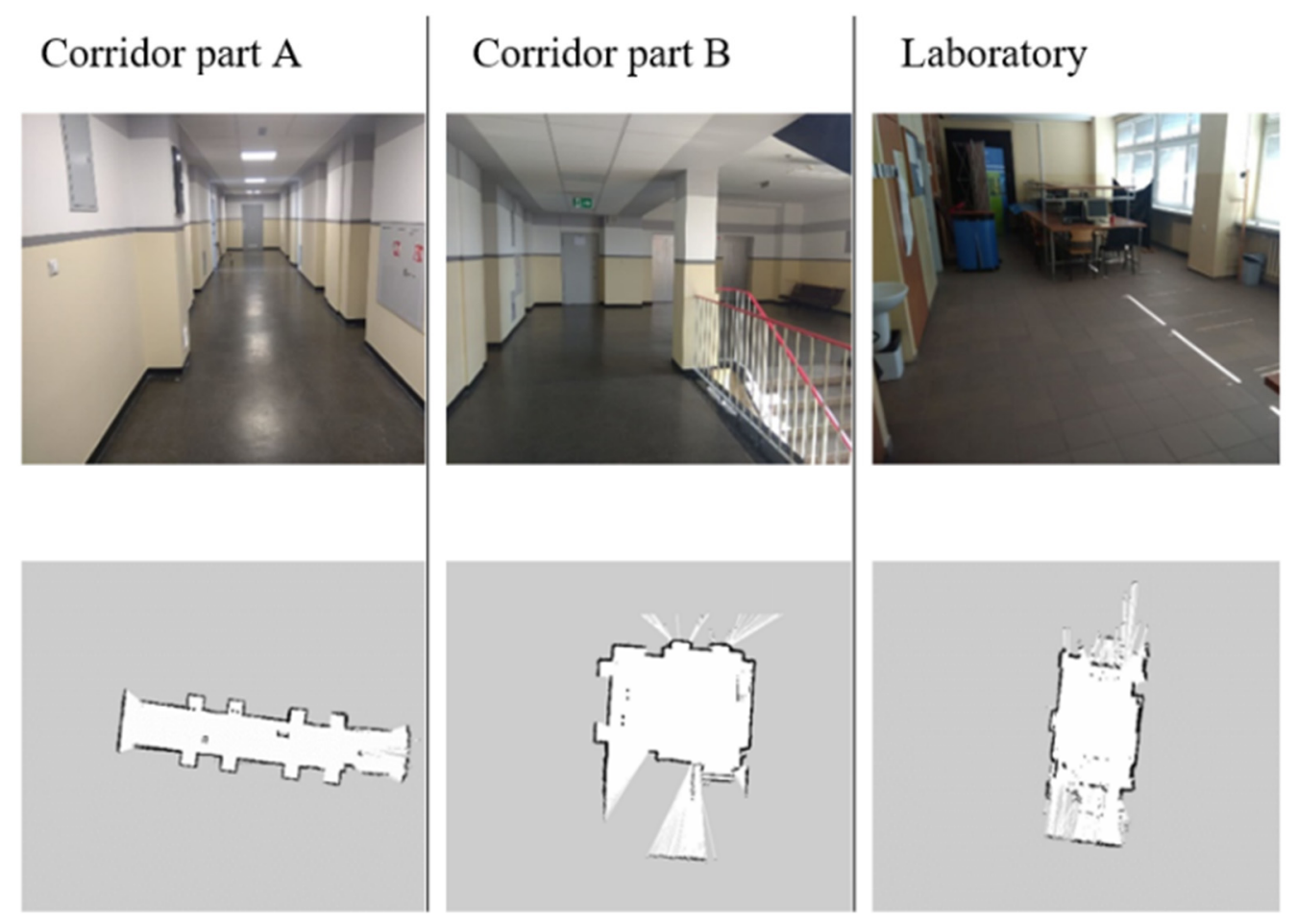

Figure 12. The test scenarios with the Lidar point map.

Figure 13 shows the distribution of UWB system tags during tests (blue circles), the external coordinate system associated with one of the tags (green circle), and the starting position of the platform (yellow circle). The initial position of the platform with respect to the local coordinate system was previously determined by the manual measure and was unchanged during tests.

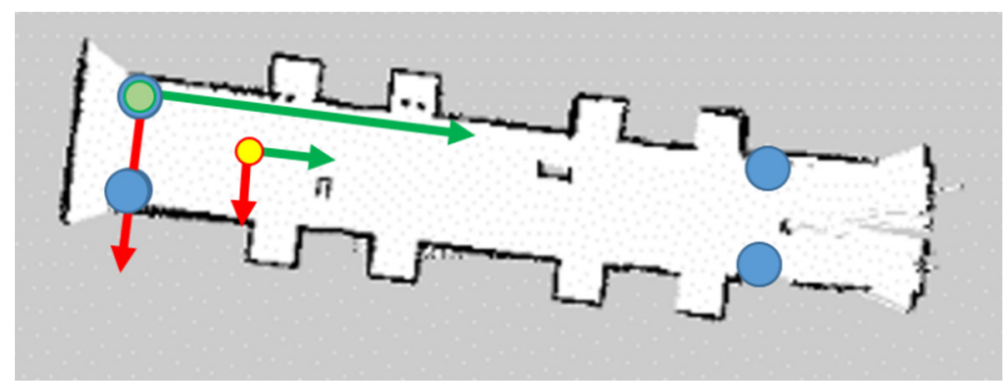

Figure 13. The distribution of the UWB system with a start point (yellow) and anchors (blue).

UWB nodes configured as an anchor are used as a reference and are required for the UWB system to operate. Their location has been marked in relevant places on room maps (blue circles in Figure 13). As mentioned, data from tests were saved using the rosbag tool. This file contains logged data with timestamps, so it is possible to restore data traffic between nodes after tests for further processing. This approach greatly facilitates development results or creating algorithms through the opportunity to work only on saved data. The Rosbag tool additionally allows to divide the saved data file into smaller parts due to the length of the test or file size. The enrolment took place on the ODROID microcomputer. 


\section{Research Results and Discussion}

Many tests have been performed indoors: on the corridor part A and B and the laboratory. The developed platform acquires the following data together with the timestamps for synchronization. Human has controlled the mobile platform, and the typical path/trajectory (2D view) is shown in Figure 14. The starting point is the bottom point of the line joining (the green square), and the stop point is above the start point (the red square). UWB raw data are shown as ' $x$ ' and the floorplan while the red line is SLAM (data from RPLidar). The reference path and the blue curve is obtained from encoders and myAHRS+ via dead reckoning.

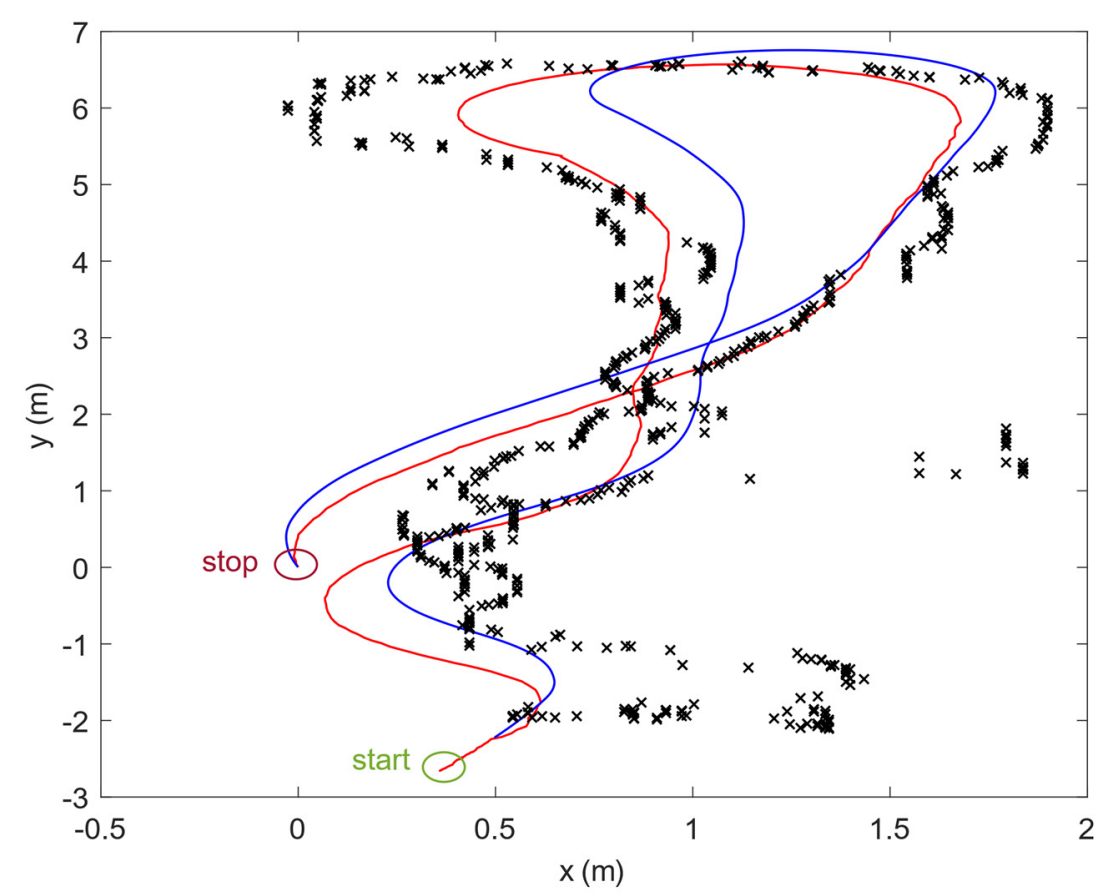

Figure 14. The trajectory determined by three methods in the environment "corridor part A." Black points-UWB, red line-SLAM, blue line-_ead reckoning.

The whole movement (corridor part A environment) took $31 \mathrm{~s}$ and allowed to collect about 1700 samples used for the dead reckoning ( $56 \mathrm{~Hz}$ data collection frequency), 590 sampled used in UWB positioning $(19 \mathrm{~Hz})$ and only 390 samples collected via SLAM $(13 \mathrm{~Hz})$.

According to the exemplary trajectory, the error in $X$ (horizontal direction) and $Y$ (vertical direction) have been evaluated. The results are presented in Figure 15 (for corridor A) where three plots can be distinguished: (top) displacement based on encoder and myAHRS+ (in blue) with respect to the $Y$ axis according to trajectory determined by SLAM (in red) from RPLidar (reference system); (middle) displacement based on encoder and myAHRS + with respect to the $\mathrm{X}$ axis (colors as previously); the last plot (bottom) shows the dead reckoning displacement error for the $\mathrm{Y}$ axis (in red) and $\mathrm{X}$ axis (in blue). 

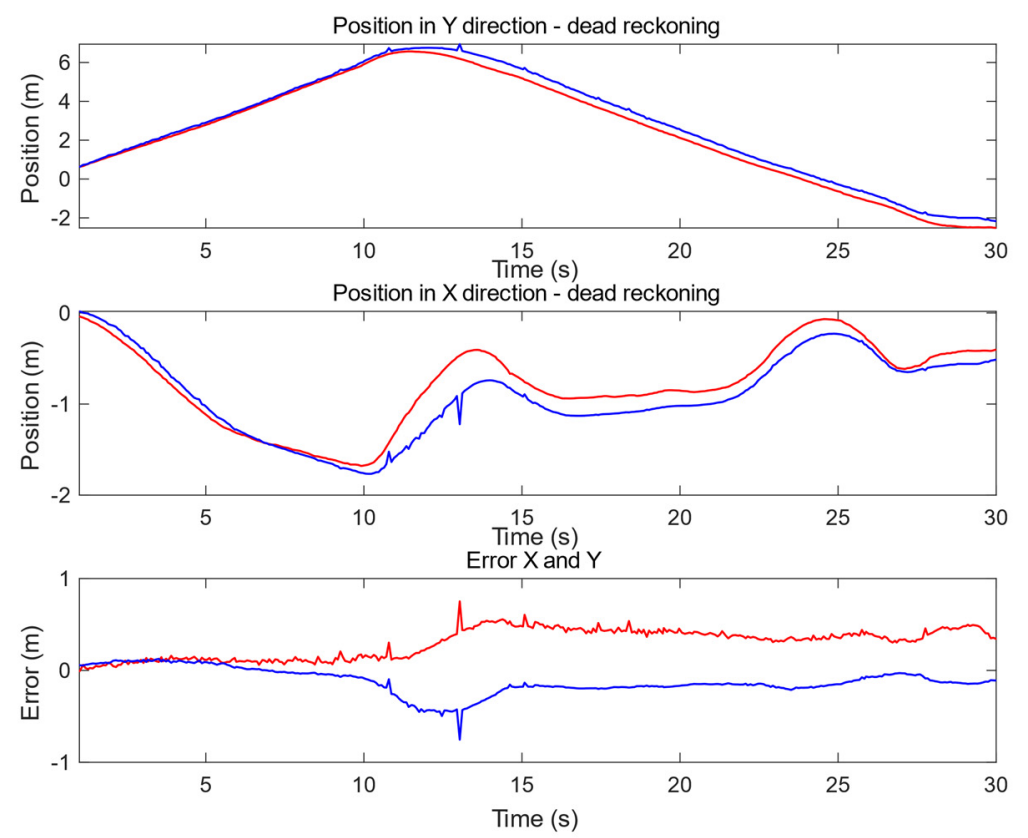

Figure 15. Plot present positioning results and error from dead reckoning in comparison to SLAM in the environment "corridor part A." DR (blue) displacement with respect to SLAM (red): (top) vertical y position, (middle) horizontal X position, (bottom) DR error-displacement vector in horizontal (blue) and vertical (red) axes.

Figure 16 presents another example for the path in corridor A for a comparison with DR (Figure 15), and presents three plots: (top) displacement based on UWB (in blue) with respect to the Y axis according to trajectory determined by SLAM (in red) from RPLidar (reference system); (middle) displacement based on UWB with respect to the $\mathrm{X}$ axis (colors as previously); (bottom) the last graph shows the UWB displacement error for $\mathrm{Y}$ axis (in red) and $\mathrm{X}$ axis (in blue).
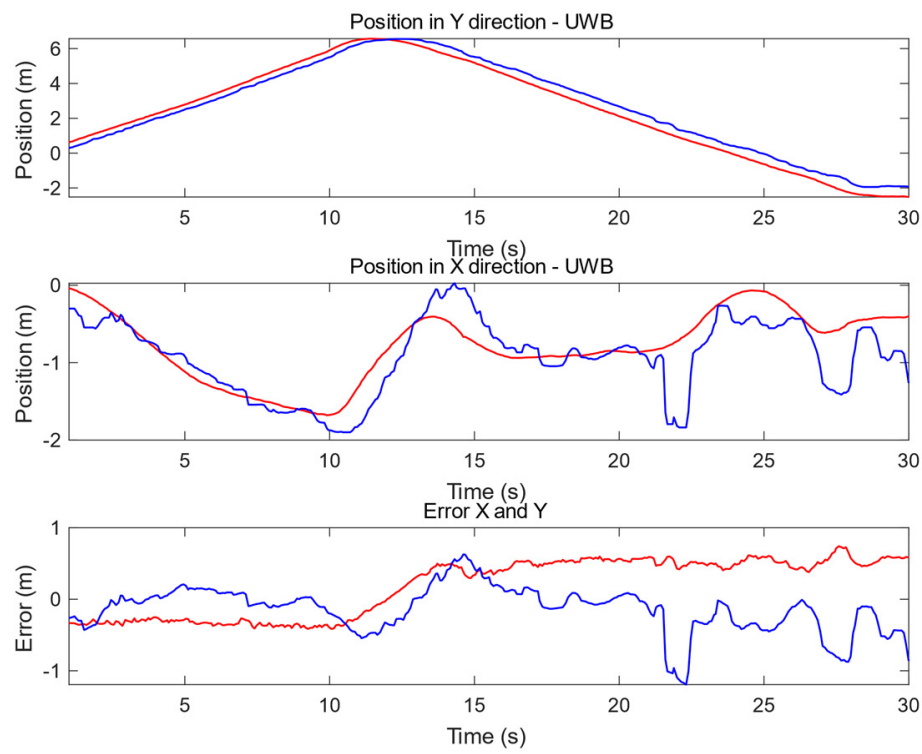

Figure 16. Plot present positioning results and error from UWB in comparison to SLAM in the environment "corridor part A." UWB (blue) displacement with respect to SLAM (red): (top) vertical y position, (middle) horizontal X position, (bottom) error-UWB displacement vector in horizontal (blue) and vertical (red) axes. 
The RMSE (root mean square error) and max deviation of the positioning using the UWB system and dead reckoning (without systematic correction) are presented in Table 2 separately for each environment and each axis.

Table 2. The positioning errors using different methods.

\begin{tabular}{cccccc}
\hline \multirow{2}{*}{ Environment } & \multirow{2}{*}{ Error [m] } & \multicolumn{2}{c}{ Dead Reckoning } & \multicolumn{2}{c}{ UWB } \\
\cline { 3 - 6 } & & $\mathbf{X}$ & $\mathbf{Y}$ & $\mathbf{X}$ & $\mathbf{Y}$ \\
\hline \multirow{2}{*}{ corridor part A } & Max & 0.75 & 0.75 & 1.19 & 0.74 \\
& RMSE & 0.18 & 0.33 & 0.38 & 0.44 \\
\hline \multirow{2}{*}{ corridor part B } & Max & 0.13 & 0.43 & 0.88 & 1.35 \\
& RMSE & 0.05 & 0.24 & 0.43 & 0.65 \\
\hline \multirow{2}{*}{ laboratory } & Max & 1.41 & 0.87 & 1.18 & 0.66 \\
& RMSE & 0.15 & 0.24 & 0.44 & 0.33 \\
\hline
\end{tabular}

When taking measurements in corridor part A, the UWB positioning system has problems due to the lack of coverage between the marker and reference point. Large metal objects such as the elevator doors near system operation can also affect the quality of the designated item. The RMSE of UWB positioning was about $1 \mathrm{~m}$ without using corrections. When the object is moving, it is better to rely on another positioning method and to use UWB as a complementary system.

The essential thing was the location of reference points and a tag. Antennas are directional, which hinders proper placement system components. When testing in the corridor near the elevators, it can be noticed that the positioning errors were higher when the mobile platform was closer to one of the reference points, but the other two were far away. The best results are obtained when the vehicle is stationary and can collect more data.

The data correction algorithm is described in Section 5, where data from one positioning system is corrected regularly using data from the more accurate system (but characterized by lower data rate). The error of the displacement using the UWB system and dead reckoning with systematic correction are presented in Table 3 separately for each environment.

Table 3. The displacement errors using different methods without and with regular correction.

\begin{tabular}{cccccc}
\hline \multirow{2}{*}{ Environment } & Correction & \multicolumn{2}{c}{ Dead Reckoning } & \multicolumn{2}{c}{ UWB } \\
\cline { 3 - 6 } & & Max [m] & RMSE [m] & Max [m] & RMSE [m] \\
\hline \multirow{5}{*}{ Corridor part A } & No & 0.84 & 0.34 & 1.21 & 0.41 \\
& Every 7 s & 0.83 & 0.27 & 0.95 & 0.28 \\
& Every 3 s & 0.74 & 0.20 & 0.78 & 0.25 \\
& Every 1 s & 0.53 & 0.08 & 0.57 & 0.15 \\
\hline \multirow{5}{*}{ Corridor part B } & No & 0.30 & 0.13 & 0.85 & 0.34 \\
& Every 7 s & 0.33 & 0.11 & 0.67 & 0.31 \\
& Every 3 s & 0.47 & 0.11 & 0.67 & 0.27 \\
& Every 1 s & 0.28 & 0.03 & 0.47 & 0.13 \\
\hline \multirow{2}{*}{ Laboratory } & No & 0.85 & 0.16 & 0.99 & 0.37 \\
& Every 3 s & 0.93 & 0.14 & 1.36 & 0.34 \\
& Every 1 s & 1.08 & 0.10 & 0.78 & 0.15 \\
\hline
\end{tabular}

The reference positions for correction are obtained from RPLidar. The displacement error (RMSE) as the time between corrections decreases. The average improvement (in reference to decreases no correction) is $23 \%$ when the corrections are made every $3 \mathrm{~s}$ and about $63 \%$ when the corrections are made every $1 \mathrm{~s}$, no matter which positioning method was used (see Table 4). 
Table 4. The improvement using systematic correction.

\begin{tabular}{cccc}
\hline Environment & Correction & Dead Reckoning & UWB \\
\hline \multirow{3}{*}{ corridor part A } & Every 7 s & $21 \%$ & $32 \%$ \\
& Every 3 s & $41 \%$ & $39 \%$ \\
& Every 1 s & $76 \%$ & $63 \%$ \\
\hline \multirow{3}{*}{ corridor part B } & Every 7 s & $15 \%$ & $9 \%$ \\
& Every 3 s & $15 \%$ & $21 \%$ \\
& Every 1 s & $77 \%$ & $62 \%$ \\
\hline \multirow{2}{*}{ laboratory } & Every 3 s & $13 \%$ & $8 \%$ \\
& Every 1 s & $38 \%$ & $59 \%$ \\
\hline \multirow{2}{*}{ Average } & Every 7 s * & $18 \%$ & $21 \%$ \\
& Every 3 s & $23 \%$ & $62 \%$ \\
\hline
\end{tabular}

Another important factor, the environment has a significant impact on the accuracy of measurements. The significant improvement in terms of periodic correction from RPLidar was noticed for the corridor part A and B, while the lowest in the laboratory class. This can be an effect of furniture which is made mainly of metal (chairs and laboratory tables). Such elements are not present in corridors. Taking into account corridors, the accuracy is much higher for part B than part A. The building structure, and a rather narrow part of corridor A (the width is appx. $3.5 \mathrm{~m}$ ), seems not to be sufficient for UWB infrastructure placement (especially in case of deployment of anchors). Moreover, the corridor is long and may act as waveguide what reduces UWB system precision. The best results have been obtained for corridor part $\mathrm{B}$ for both dead reckoning and UWB systems. This is a result of UWB infrastructure placement as all anchors are not directly by the walls (like in corridor part A). These are the reasons why both systems (dead reckoning and UWB) require correction depending on the environment in which the measurements are carried out. On the other hand, in cases were environment conducive to the UWB system working conditions, both systems without correction give the highest possible accuracy. Without doubt, the RPLidar has the best conditions for simultaneous localization and mapping and gives the most accurate position. The results of the tests of the UWB system have been registered and are available in the form of a movie [31] (https://www.youtube.com/watch?v=-JsLYsDf_n0).

\section{Conclusions}

The research conducted shows the efficiency of the UWB positioning system in which accuracy can be increased by using RPLidar data for periodic correction. Both evaluated positioning systems, i.e., dead reckoning and UWB, have their advantages and disadvantages. The main advantage of using the only odometry is that no additional infrastructure is required for localization of the ego-vehicle. However, to detect other vehicles, a sensor like a lidar is necessary. The RPLidar seems to combine advantages: no additional infrastructure and precise perception of the environment, but there a lack of simultaneous communication and huge amounts of data to be processed for SLAM. The information from the RPLidar comes with an unspecified time interval that leads to surrounding gaps. Furthermore, SLAM needs some sort of landmarks for localization and does not work in sparse environments. The UWB positioning system is not as precise as RPLidar and the data are not so frequent as from odometry, it also requires infrastructure, but it allows for the use of offline maps and it also consists of an additional communication channel. For safety systems, like autonomous driving, the importance of redundancy is high. Thus, it is important to detect critical situations and determine the position using all three systems. In the case of relatively small differences in the determined position between SLAM and the dead reckoning or the UWB system, only SLAM can be used, while in other cases, 
a positioning system should rely on the dead reckoning, adjusted from time to time by measurements from UWB system for global localization.

Comparing UWB systems and dead reckoning, it can be stated that dead reckoning is more resistant to measurement noise, and its positioning better reflects the trajectories of the route. On the other hand, the error will increase over time as opposed to positioning using the UWB system. SLAM was used as a reference because it is the best way to determine the position of the platform, but only in places where there are enough characteristic points of the environment, i.e., indoors, but not necessarily outside.

Another big advantage in favor of using the UWB system is its greater resistance to work in an environment where the positioned object is obscured (if there are no conditions of direct LOS-a line of sight). In addition, since the UWB system works at a higher frequency than SLAM, it is possible to use more frequent position information for more detailed filtration, e.g., complementary filtration or Kalman filter. Further, the last advantage of the UWB is its communication capability that can be utilized in the new infrastructure across smart cities or to improve the quality of ADAS functionality. The entire research indicates also that indoor localization depends on the environment and it requires the positioning algorithm to include a method for recognizing the environmental conditions in which the measurements take place.

Author Contributions: D.G. conceived the experiment; D.G. and A.Z. conceptualization, M.C. and A.G. collected the data and performed the experiments; K.H., K.P., A.Z. and D.G. analyzed the data; M.C. and A.G. implemented the algorithms; K.H., K.P., M.C., A.G. and D.G. wrote the paper, A.B., A.Z. and D.G. corrected the paper; K.P., K.H. and A.Z. performed a literature overview; D.G. project supervision. All authors have read and agreed to the published version of the manuscript.

Funding: This research was funded by the Polish Ministry of Science and Higher Education partially by Statutory Research BK-284/RAU11/2020 (02/140/BK_20/0004) and BK-281/RAu8/2020 (02/110/BK_20/0003), and partially by Young Researchers funds of Department of Electronics, Electrical Engineering and Microelectronics, Faculty of Automatic Control, Electronics and Computer Science, Silesian University of Technology, Gliwice, Poland, and partially by Research project No. NOR/POLNOR/CoBotAGV/0027/2019.

Conflicts of Interest: The authors declare no conflict of interest. The funders had no role in the design of the study; in the collection, analyses, or interpretation of data; in the writing of the manuscript, or in the decision to publish the results.

\section{References}

1. Horowitz, R.; Varaiya, P. Control design of an automated highway system. Proc. IEEE 2000, 88, 913-925. [CrossRef]

2. Bergenhem, C.; Shladover, S.; Coelingh, E.; Englund, C.; Tsugawa, S. Overview of Platooning Systems. In Proceedings of the 19th ITS World Congress, Vienna, Austria, 22-26 October 2012.

3. Zhang, F.; Knoll, A. Vehicle Detection Based on Probability Hypothesis Density Filter. Sensors 2016, 16, 510. [CrossRef] [PubMed]

4. Kavathekar, P.; Chen, Y. Vehicle Platooning: A Brief Survey and Categorization. In Proceedings of the 2011 ASME/IEEE International Conference on Mechatronic and Embedded Systems and Applications, Parts A and B, Washington, DC, USA, 28-31 August 2011; ASMEDC: Washington, DC, USA, 2011; Volume 3, pp. 829-845.

5. Tsugawa, S.; Kato, S.; Aoki, K. An automated truck platoon for energy saving. In Proceedings of the 2011 IEEE/RSJ International Conference on Intelligent Robots and Systems, San Francisco, CA, USA, 22-24 October 2011; pp. 4109-4114.

6. Bengler, K.; Dietmayer, K.; Farber, B.; Maurer, M.; Stiller, C.; Winner, H. Three Decades of Driver Assistance Systems: Review and Future Perspectives. IEEE Intell. Transp. Syst. Mag. 2014, 6, 6-22. [CrossRef]

7. Alarifi, A.; Al-Salman, A.; Alsaleh, M.; Alnafessah, A.; Al-Hadhrami, S.; Al-Ammar, M.; Al-Khalifa, H. Ultra Wideband Indoor Positioning Technologies: Analysis and Recent Advances. Sensors 2016, 16, 707. [CrossRef] [PubMed]

8. Sheng, H.; Orlik, P.; Haimovich, A.M.; Cimini, L.J.; Zhang, J. On the spectral and power requirements for ultra-wideband transmission. In Proceedings of the IEEE International Conference on Communications, Anchorage, AK, USA, 11-15 May 2003; Volume 1, pp. 738-742. 
9. Han, Y.; Wei, C.; Li, R.; Wang, J.; Yu, H. A Novel Cooperative Localization Method Based on IMU and UWB. Sensors 2020, 20, 467. [CrossRef] [PubMed]

10. Błachuta, M.; Czyba, R.; Janusz, W.; Szafrański, G. Data Fusion Algorithm for the Altitude and Vertical Speed Estimation of the VTOL Platform. J. Intell. Robot. Syst. 2014, 74, 413-420. [CrossRef]

11. Xie, S.; Pan, C.; Peng, Y.; Liu, K.; Ying, S. Large-Scale Place Recognition Based on Camera-LiDAR Fused Descriptor. Sensors 2020, 20, 2870. [CrossRef] [PubMed]

12. Ziebinski, A.; Bregulla, M.; Fojcik, M.; Kłak, S. Monitoring and Controlling Speed for an Autonomous Mobile Platform Based on the Hall Sensor. In Computational Collective Intelligence; Nguyen, N.T., Papadopoulos, G.A., Jędrzejowicz, P., Trawiński, B., Vossen, G., Eds.; Lecture Notes in Computer Science; Springer International Publishing: Cham, Switzerland, 2017; Volume 10449, pp. 249-259. ISBN 978-3-319-67076-8.

13. Miura, J.; Kanda, T.; Shirai, Y. An active vision system for real-time traffic sign recognition. In Proceedings of the ITSC2000. 2000 IEEE Intelligent Transportation Systems. Proceedings (Cat. No.00TH8493), Dearborn, MI, USA, 1-3 October 2000; pp. 52-57.

14. Assidiq, A.A.; Khalifa, O.O.; Islam, M.R.; Khan, S. Real time lane detection for autonomous vehicles. In Proceedings of the 2008 International Conference on Computer and Communication Engineering, Kuala Lumpur, Malaysia, 13-15 May 2008; pp. 82-88.

15. Sim, H.; Lee, S.; Lee, B.; Kim, S.-C. Road structure classification through artificial neural network for automotive radar systems. Sonar Navig. IET Radar 2019, 13, 1010-1017. [CrossRef]

16. Daza, I.; Bergasa, L.; Bronte, S.; Yebes, J.; Almazán, J.; Arroyo, R. Fusion of Optimized Indicators from Advanced Driver Assistance Systems (ADAS) for Driver Drowsiness Detection. Sensors 2014, 14, 1106-1131. [CrossRef] [PubMed]

17. Grzechca, D.; Ziębiński, A.; Rybka, P. Enhanced Reliability of ADAS Sensors Based on the Observation of the Power Supply Current and Neural Network Application. In Computational Collective Intelligence; Nguyen, N.T., Papadopoulos, G.A., Jędrzejowicz, P., Trawiński, B., Vossen, G., Eds.; Lecture Notes in Computer Science; Springer International Publishing: Cham, Switzerland, 2017; Volume 10449, pp. 215-226. ISBN 978-3-319-67076-8.

18. Cupek, R.; Ziębiński, A.; Drewniak, M.; Fojcik, M. Application of OPC UA Protocol for the Internet of Vehicles. In Computational Collective Intelligence; Nguyen, N.T., Papadopoulos, G.A., Jędrzejowicz, P., Trawiński, B., Vossen, G., Eds.; Lecture Notes in Computer Science; Springer International Publishing: Cham, Switzerland, 2017; Volume 10449, pp. 272-281. ISBN 978-3-319-67076-8.

19. Martínez, A.; Cañibano, E.; Romo, J. Analysis of Low Cost Communication Technologies for V2I Applications. Appl. Sci. 2020, 10, 1249. [CrossRef]

20. Ogawa, T.; Sakai, H.; Suzuki, Y.; Takagi, K.; Morikawa, K. Pedestrian detection and tracking using in-vehicle lidar for automotive application. In Proceedings of the 2011 IEEE Intelligent Vehicles Symposium (IV), Baden-Baden, Germany, 5-9 June 2011; pp. 734-739.

21. Shladover, S.E.; Su, D.; Lu, X.-Y. Impacts of Cooperative Adaptive Cruise Control on Freeway Traffic Flow. Transp. Res. Rec. J. Transp. Res. Board 2012, 2324, 63-70. [CrossRef]

22. Kim, I.-H.; Bong, J.-H.; Park, J.; Park, S. Prediction of Driver's Intention of Lane Change by Augmenting Sensor Information Using Machine Learning Techniques. Sensors 2017, 17, 1350. [CrossRef] [PubMed]

23. Wang, J.; Sun, X.; Guo, J. A Region Tracking-Based Vehicle Detection Algorithm in Nighttime Traffic Scenes. Sensors 2013, 13, 16474-16493. [CrossRef]

24. Pozyx Specs Developer Tag (Headerless). Available online: https://www.pozyx.io/shop/product/developertag-headerless-70 (accessed on 25 May 2020).

25. Grzechca, D.; Hanzel, K.; Paszek, K. Accuracy analysis for object positioning on a circular trajectory based on the UWB location system. In Proceedings of the 2018 14th International Conference on Advanced Trends in Radioelecrtronics, Telecommunications and Computer Engineering (TCSET), Slavske, Ukraine, 20-24 February 2018; pp. 69-74.

26. Grzechca, D.; Tokarz, K.; Hanzel, K.; Pokucinski, S. On fundamental issues on creating autonomous platform for UWB navigation system. J. Control Eng. Appl. Inform. 2020, 22, 84-93.

27. Fang, B.T. Trilateration and extension to Global Positioning System navigation. J. Guid. Control Dyn. 1986, 9 , 715-717. [CrossRef] 
28. Hellmers, H.; Eichhorn, A.; Norrdine, A.; Blankenbach, J. Indoor localisation for wheeled platforms based on IMU and artificially generated magnetic field. In Proceedings of the 2014 Ubiquitous Positioning Indoor Navigation and Location Based Service (UPINLBS), Corpus Christ, TX, USA, 20-21 November 2014; pp. 255-264.

29. Grzechca, D.; Paszek, K. Short-term positioning accuracy based on mems sensors for smart city solutions. Pol. Acad. Sci. Comm. Metrol. Sci. Instrum. 2019, 26, 95-107.

30. Kohlbrecher, S.; von Stryk, O.; Meyer, J.; Klingauf, U. A flexible and scalable SLAM system with full 3D motion estimation. In Proceedings of the 2011 IEEE International Symposium on Safety, Security, and Rescue Robotics, Kyoto, Japan, 1-5 November 2011; pp. 155-160.

31. Grzechca, D.; Hanzel, K.; Paszek, K. The Movie from Tests of the Developed UWB System. Available online: https://www.youtube.com/watch?v=-JsLYsDf_n0 (accessed on 29 May 2020).

(C) 2020 by the authors. Licensee MDPI, Basel, Switzerland. This article is an open access article distributed under the terms and conditions of the Creative Commons Attribution (CC BY) license (http://creativecommons.org/licenses/by/4.0/). 